\title{
OPEN Evident hypopigmentation without other ocular deficits in Dutch patients with oculocutaneous albinism type 4
}

\author{
C. C. Kruijt ${ }^{1,2 \bowtie}$, N. E. Schalij-Delfos ${ }^{2}$, G. C. de Wit ${ }^{1}$, R. J. Florijn ${ }^{3}$ \& M. M. van Genderen ${ }^{1,4}$
}

To describe the phenotype of Dutch patients with oculocutaneous albinism type 4 (OCA4), we collected data on pigmentation (skin, hair, and eyes), visual acuity (VA), nystagmus, foveal hypoplasia, chiasmal misrouting, and molecular analyses of nine Dutch OCA4 patients from the Bartiméus Diagnostic Center for complex visual disorders. All patients had severely reduced pigmentation of skin, hair, and eyes with iris transillumination over 360 degrees. Three unrelated OCA4 patients had normal VA, no nystagmus, no foveal hypoplasia, and no misrouting of the visual pathways. Six patients had poor visual acuity ( 0.6 to 1.0 logMAR), nystagmus, severe foveal hypoplasia and misrouting. We found two novel variants in the SLC45A2 gene, c.310C > T; (p.Pro104Ser), and c.1368+3_1368+9del; (p.?). OCA4 patients of this Dutch cohort all had hypopigmentation of skin, hair, and iris translucency. However, patients were either severely affected with regard to visual acuity, foveal hypoplasia, and misrouting, or visually not affected at all. We describe for the first time OCA4 patients with an evident lack of pigmentation, but normal visual acuity, normal foveal development and absence of misrouting. This implies that absence of melanin does not invariably lead to foveal hypoplasia and abnormal routing of the visual pathways.

Oculocutaneous albinism (OCA) is characterized by hypopigmentation of skin, hair, and eyes, reduced visual acuity (VA), nystagmus, foveal hypoplasia, and misrouting of the visual pathways ${ }^{1}$. Oculocutaneous albinism type four (OCA4) is one of eight known non-syndromic types of albinism with autosomal recessive inheritance. To date seven genes are known causing non-syndromic OCA, OCA5 concerns a chromosomal region containing a gene yet to be identified ${ }^{2}$. OCA4 is caused by variants in the SLC45A2 gene, mapped to chromosome 5p13 (OCA4; OMIM \#606,574). Its protein, the membrane-associated transporter (MATP), is located in melanosomes. The exact function of MATP is unknown, but it probably plays an important role in the membrane transport of melanosomes ${ }^{3}$. Knockdown of MATP results in a lower $\mathrm{pH}$ level in the melanosomes ${ }^{4}$. Tyrosinase activity is inhibited by an acidic environment, and consequently variants in SLC45A2 reduce melanin synthesis by lowering or inhibiting tyrosinase The first OCA4 patient, a Turkish patient reported in 2001 by Newton et al., showed complete lack of pigmentation of skin, hair and eyes ${ }^{5}$. Since then, many patients have been described with variable phenotypes, from complete absence of pigmentation to subtle hypopigmentation only ${ }^{1,6-30}$. World prevalence of OCA4 is estimated around 1:100.000, which is $3-19 \%$ of all OCA cases ${ }^{6,8,15,16,18,25,26,31-33}$. In Japan OCA4 is more common, with a frequency of $27 \%$ of all OCA cases ${ }^{34}$. In the Netherlands, approximately $4 \%$ of OCA is caused by variants in SLC45A2 ${ }^{1}$. In this study, we describe our cohort of OCA4 patients in the Netherlands, including detailed ophthalmic information.

\footnotetext{
${ }^{1}$ Bartiméus Diagnostic Center for Complex Visual Disorders, Zeist, The Netherlands. ${ }^{2}$ Department of Ophthalmology, Leiden University Medical Center, Leiden, The Netherlands. ${ }^{3}$ Department of Clinical Genetics, Amsterdam University Medical Center, Location AMC, Amsterdam, the Netherlands. "Department of Ophthalmology, University Medical Center Utrecht, Utrecht, The Netherlands. ${ }^{\circledR}$ email: c.c.kruijt@lumc.nl
} 


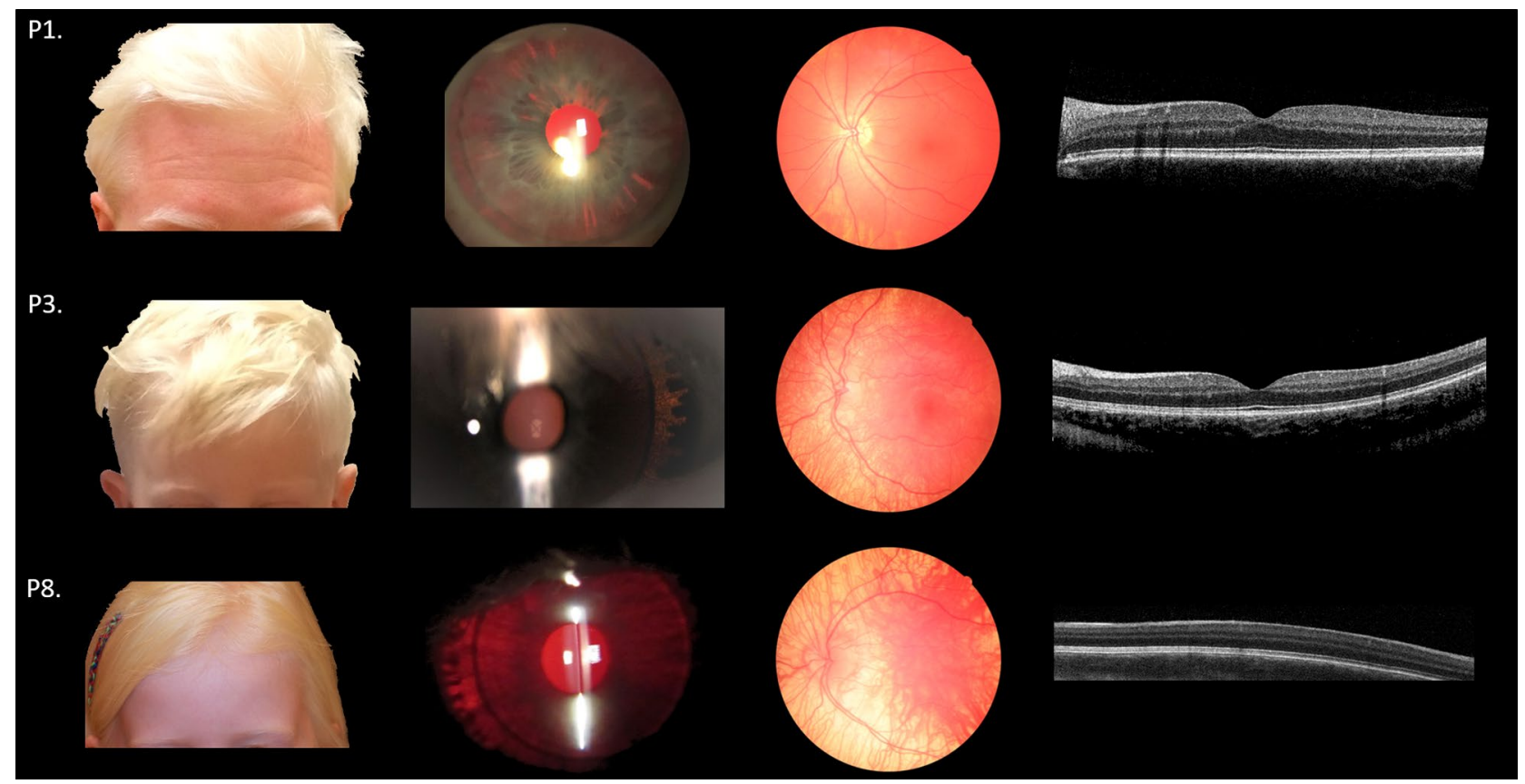

Figure 1. Clinical features of OCA4 patients. Pigmentation of skin and hair, iris translucency, fundus pigmentation, and optical coherence tomography of patients P1, P3, and P8. Note the complete absence of pigment of skin and hair in P1 and P3, iris translucency, fundus hypopigmentation, and completely normal foveal structure. In P8 pigmentation is comparable to P1 and P3, but no foveal pit, widening of the outer nuclear layer or elongation of the photoreceptors can be detected (foveal hypoplasia grade four according to the scheme of Thomas et al. ${ }^{35}$ ).

\section{Patients and methods}

This study was approved by the Medical Ethics Committee of the Leiden University Medical Center and adhered to the tenets of the Declaration of Helsinki. Informed consent was obtained from all participants and/or legal guardians. An additional informed consent was obtained for the publication of the images from the patients in Fig. 1.

We identified nine patients from six families with two variants in SLC45A2 from the databases of Bartiméus Diagnostic Center for complex visual disorders. Analyses were performed according to the ACMG guidelines by the laboratory of the Amsterdam University Medical Center, location AMC, a certified clinical laboratory. An albinism panel was screened with next-generation sequencing (NGS) for variants in the following albinism associated genes: GPR143 (OA1), TYR (OCA1), OCA2 (OCA2), TYRP1 (OCA3), SLC45A2 (OCA4), SLC24A5 (OCA6), LRMDA (OCA7), LYST (Chédiak-Higashi) and HPS1, AP3B1, HPS3, HPS4, HPS5, HPS6, DTNBP1, BLOC1S3, BLOC1S6 (Hermansky-Pudlak 1-9: respectively). Eight patients were of Dutch origin, patient 9 was of Syrian-Turkish descent. None of the patients had any interventions affecting visual acuity. We retrospectively collected data on pigmentation levels of skin, hair, and eyes, visual acuity (VA), and other ophthalmic features of albinism, -i.e. nystagmus, foveal hypoplasia, and misrouting of the optic nerve fibers. We obtained spectraldomain optical coherence tomography (OCT) scans with RT-Vue (Optovue, Fremont, CA) to assess the amount of foveal hypoplasia in all patients. To ensure we captured the foveal region we used line scans as well as MM6 scans (12 radial line scans). In patients P1, P3, and P8, we also obtained scans with Canon OCT A-1 (Kawasaki, Japan), not affecting the grade, but with a qualitatively better image. We graded the foveal hypoplasia according to the scheme of Thomas et al. with grade 1 and 2 not having incursion of the inner retinal layers, and grade 3 and 4 also affecting the photoreceptor differentiation ${ }^{35}$. Multichannel visually evoked potentials (VEPs) were recorded to determine misrouting. We used pattern onset VEPs for the assessment of misrouting in adults, and older children, and we used flash VEP for young children, according to ISCEV standards ${ }^{36,37}$. We used the differential signal of the electrodes on the left hemisphere minus that of the electrodes on the right hemisphere to calculate the chiasm coeffeicient. To conclude if misrouting was present we used the cutoff values calculated by Kruijt et al. ${ }^{37}$.

\section{Results}

Patient data are shown in Table 1. P1, P2, and P3 were unrelated. They had very pale skin, were unable to tan, were very sensitive to sun exposure, had white to very light blond hair, white eyelashes, and blue irides, translucent over 360 degrees (grade 3-4 iris translucency ${ }^{1}$ ). P1 had grade 1 fundus hypopigmentation (only hypopigmention in the (mid)periphery ${ }^{1}$ ), but in P2, and P3 choroid vessels were easiliy visible in the posterior pole (grade 2). The main complaint of the patients was photophobia. P1 and P2 had good VA of -0.1 logMAR (1.25 Snellen). VA of P3, a four year old boy, was $0.3 \log$ MAR ( 0.5 Snellen), which was within the normal range for his age. None of 


\begin{tabular}{|c|c|c|c|c|c|c|c|c|c|}
\hline $\begin{array}{l}\text { Subject age/ } \\
\text { gender }\end{array}$ & \begin{tabular}{|l|} 
Variants SLC45A2 \\
(Chr5: NM_016180.4)
\end{tabular} & $\begin{array}{l}\text { Pigmentation } \\
\text { skin and hair }\end{array}$ & *VA & Refractive error & Nystagmus & Iris translucency & \begin{tabular}{|l} 
Fundus \\
pigmentation $^{\mathrm{a}}$
\end{tabular} & $\begin{array}{l}\text { Foveal } \\
\text { hypoplasiab }^{\text {b }}\end{array}$ & Misrouting \\
\hline $\begin{array}{l}\mathrm{P} 1 \\
31 / \text { male }\end{array}$ & \begin{tabular}{|l|} 
c.1502C $>$ A \\
(p.Ala501Asp) \\
c.1567G $>$ A \\
(p.Ala523Thr)
\end{tabular} & $\begin{array}{l}\text { White eyelashes, } \\
\text { white hair, pale } \\
\text { skin }\end{array}$ & -0.1 & $\begin{array}{l}+0.50 \mathrm{D} /-2.50 \times 160 \\
+0.25 \mathrm{D} /-2.00 \times 28\end{array}$ & No & Grade 4 & Grade 1 & No hypoplasia & No \\
\hline $\begin{array}{l}\text { P2 } \\
\text { 18/female }\end{array}$ & $\begin{array}{l}\text { c. } 125 \mathrm{~T}>\mathrm{C} \\
\text { (pMet42Thr) } \\
\text { c.310C }>\mathrm{T} \\
\text { (p.Pro104Ser) } \\
\end{array}$ & $\begin{array}{l}\text { Blond eyelashes, } \\
\text { very light blond } \\
\text { hair, pale skin }\end{array}$ & -0.1 & $\begin{array}{l}+3.00 \mathrm{D} /-0.50 \times 167 \\
+3.00 \mathrm{D} /-0.50 \times 34\end{array}$ & No & Grade 3 & Grade 2 & No hypoplasia & No \\
\hline $\begin{array}{l}\text { P3 } \\
4 / \text { male }\end{array}$ & \begin{tabular}{|l|} 
c.1082 T >C \\
(p.Leu361Pro) \\
c.1368+3_1368+9del \\
(p.?)
\end{tabular} & $\begin{array}{l}\text { White eyelashes, } \\
\text { white hair, pale } \\
\text { skin }\end{array}$ & 0.3 & $\begin{array}{l}+4.50 \mathrm{D} /-0.25 \times 180 \\
+4.50 \mathrm{D} /-0.25 \times 180\end{array}$ & No & Grade 3 & Grade 2 & No hypoplasia & No \\
\hline $\begin{array}{l}\mathrm{P} 4 \\
31 / \text { female }\end{array}$ & $\begin{array}{l}\text { c.533_534dup } \\
\text { (p.Gly179Argfs } 23 \text { ) } \\
\text { c.1082 T >C } \\
\text { (p.Leu361Pro) }\end{array}$ & $\begin{array}{l}\text { White eyelashes, } \\
\text { white hair, pale } \\
\text { skin }\end{array}$ & 0.6 & $\begin{array}{l}+4.00 \mathrm{D} /-4.75 \times 11 \\
+1.75 \mathrm{D} /-3.00 \times 180\end{array}$ & Yes & Grade 4 & Grade 2 & Grade 4 & Yes \\
\hline $\begin{array}{l}\text { P5 } \\
48 / \text { female }\end{array}$ & $\begin{array}{l}\text { c.533_534dup } \\
\text { (p.Gly179Argfs }{ }^{*} 23 \text { ) } \\
\text { c.1082 T >C } \\
\text { (p.Leu361Pro) }\end{array}$ & $\begin{array}{l}\text { White eyelashes, } \\
\text { white hair, pale } \\
\text { skin }\end{array}$ & 1.0 & $\begin{array}{l}+0.50 \mathrm{D} /-4.50 \times 98 \\
+1.00 \mathrm{D} /-3.00 \times 83\end{array}$ & Yes & Grade 4 & Grade 2 & Grade 4 & Yes \\
\hline $\begin{array}{l}\mathrm{P} 6 \\
12 / \text { male }\end{array}$ & \begin{tabular}{|l|} 
Homozygous \\
c.264del \\
(p.Gly89Aspfs $\left.{ }^{\star} 24\right)$ \\
\end{tabular} & $\begin{array}{l}\text { White eyelashes, } \\
\text { white hair, pale } \\
\text { skin }\end{array}$ & 0.9 & $\begin{array}{l}+3.50 \mathrm{D} /-2.75 \times 180 \\
+5.00 \mathrm{D} /-2.00 \times 176\end{array}$ & Yes & Grade 4 & Grade 3 & Grade 4 & Yes \\
\hline $\begin{array}{l}\mathrm{P} 7 \\
12 / \text { male }\end{array}$ & $\begin{array}{l}\text { Homozygous } \\
\text { c.264del } \\
\text { (p.Gly89Aspfs*24) }\end{array}$ & $\begin{array}{l}\text { White eyelashes, } \\
\text { white hair, pale } \\
\text { skin }\end{array}$ & 0.7 & $\begin{array}{l}+4.00 \mathrm{D} /-2.50 \times 169 \\
+3.25 \mathrm{D} /-2.50 \times 164\end{array}$ & Yes & Grade 4 & Grade 3 & Grade 4 & Yes \\
\hline $\begin{array}{l}\mathrm{P} 8 \\
6 / \text { female }\end{array}$ & $\begin{array}{l}\text { Homozygous } \\
\text { c.264del } \\
\left.\text { (p.Gly89Aspfs }{ }^{\star} 24\right)\end{array}$ & $\begin{array}{l}\text { White eyelashes, } \\
\text { white hair, pale } \\
\text { skin }\end{array}$ & 0.8 & $\begin{array}{l}+3.25 \mathrm{D} /-2.75 \times 178 \\
+5.50 \mathrm{D} /-3.50 \times 8\end{array}$ & Yes & Grade 4 & Grade 3 & Grade 4 & Yes \\
\hline $\begin{array}{l}\text { P9 } \\
5 / \text { male }\end{array}$ & $\begin{array}{l}\text { Homozygous } \\
\text { c.277G>A } \\
\text { (p.Asp93Asn) }\end{array}$ & $\begin{array}{l}\text { Blond eyelashes, } \\
\text { very light blond } \\
\text { hair, pale skin }\end{array}$ & 0.6 & $\begin{array}{l}+2.25 \mathrm{D} /-1.75 \times 10 \\
+3.00 \mathrm{D} /-1.50 \times 175\end{array}$ & Yes & Grade 4 & $\begin{array}{l}\text { Hypopigmenta- } \\
\text { tion, no fundus } \\
\text { image for grad- } \\
\text { ing }\end{array}$ & $\begin{array}{l}\text { Hypoplasia, no } \\
\text { OCT for grading }\end{array}$ & Yes \\
\hline
\end{tabular}

Table 1. Clinical and molecular findings. ${ }^{*}$ Visual acuity in $\operatorname{logMAR},{ }^{a}$ According to the grading of Kruijt et al. ${ }^{1}$, ${ }^{\mathrm{b}}$ According to the grading of Thomas et al. ${ }^{35}$.

the three patients had nystagmus, foveal hypoplasia, or misrouting. Misrouting was absent in pattern onset as well as flash VEP in all three patients. They were diagnosed with OCA4 based on evident hypopigmentation, and two disease causing variants in the SLC45A2 gene. None of the patients carried variants in other albinism associated genes, including any of the known hypomorphic alleles in TYR and OCA2. P2 and P3 carried novel variants, c.310C > T; (p.Pro104Ser), and c.1368+3_1368+9del (p.?) respectively. (Table 1) In all three patients, segregation analysis showed that the variants were located on different alleles. Iris transillumination, fundus images, and OCT-scans of P1 and P3 are illustrated in Fig. 1.

P4 and P5 were sisters, P6 and P7 twin brothers. P9 did not have siblings with OCA4. P4-P9 also showed severe lack of pigmentation of skin, hair, and eyes, comparable to patients P1, P2, and P3. But, in contrast, visual function was severely affected. They all had poor VA (0.6 to $1.0 \operatorname{logMAR})$, nystagmus, severe foveal hypoplasia (grade four ${ }^{35}$ ), and misrouting. (Table1, and Fig. 1). Examples of the results of pattern onset and flash VEP-testing are shown in Fig. 2 (P1 and P4 pattern onset, and P3 and P9 flash VEP).

\section{Discussion}

In this report, we describe for the first time three unrelated Dutch OCA4 patients, with evident hypopigmentation of skin, hair, and iris, but normal visual acuity, foveal development and routing of the visual pathways. Both missense variants found in P1, c.1502C > A; p.Ala501Asp and c.1567G > A; p.Ala523Thr, are localized in the major facilitator superfamily domain. c.1502C > A. The p.Ala501Asp variant was previously reported in two heterozygous albinism patients, one was severely affected (not specified) and the other patient had mild

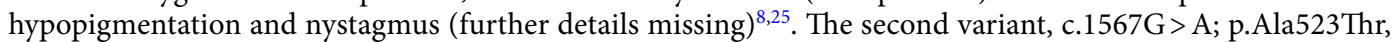
was described in one compound heterozygous albinism patient without phenotypic description ${ }^{38}$. The missense variants c.125 T > C and c.310C > T found in P2 predict the amino acid substitution p.Met42Thr and p.Pro104Ser respectively, changing a highly conserved amino acid. The second variant c.310C > T; p.Pro104Ser was novel, and our laboratory classified it as likely pathogenic, Grantham distance (74), AGVGD C65, SIFT Deleterious, Polyphen probably damaging. P3 had one previously reported variant, c.1082 T > C; p.Leu361Pro, and one novel variant, c. $1368+3 \_1368+9 \mathrm{del}$ p.? The missense variant c. $1082 \mathrm{~T}>\mathrm{C}$; p.Leu361Pro has been reported in a homozygous patient that was severely affected in melanin synthesis and visual function ${ }^{26}$. The variant was also found in severely affected P4 and P5 from our series. The novel variant c.1368+3_1368+9del p.? probably results in abnormal splicing of the SLC45A2 RNA, causing a frameshift by skipping exon 6 according to three out of four prediction programs. Prediction programs scores were: SpliceSitefinder wildtype (WT) 76.6, variant 14.7; MaxEntScan WT 5.4, variant 3.3; NNSPLICE WT 0.6, variant no prediction; Genesplicer WT no predicition, and variant no prediction. The pathological significance of the novel variants has to be further investigated, for 


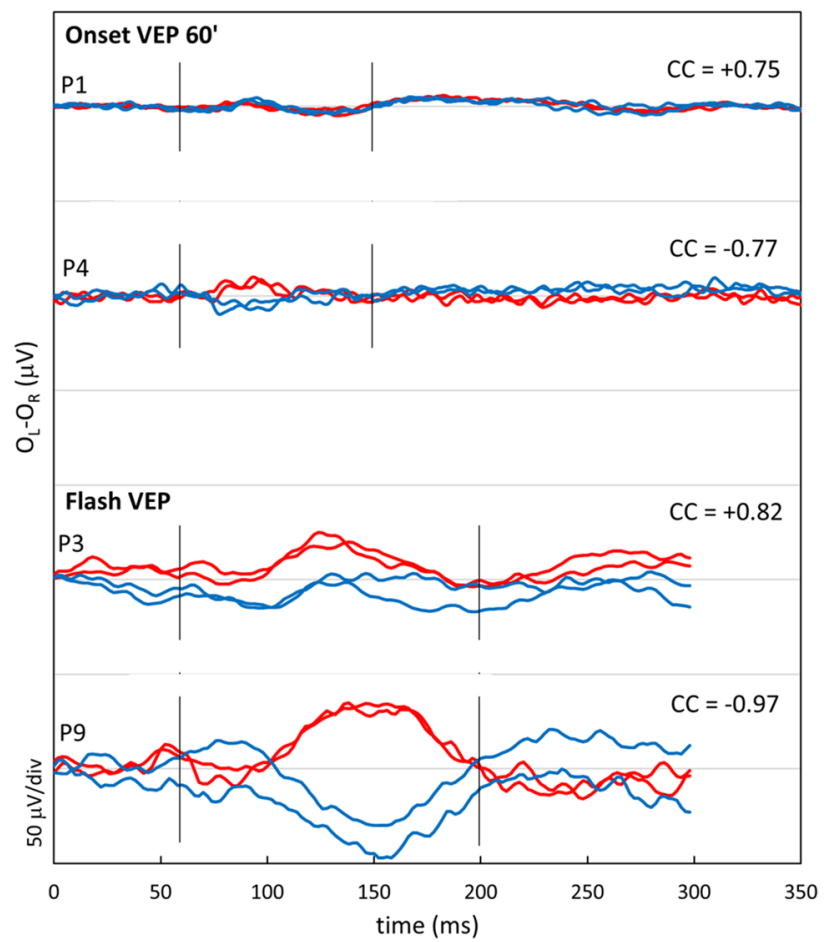

Figure 2. Visually evoked potentials. Difference signal of the pattern onset and flash visually evoked potentials (VEP) between the electrode on left hemisphere and right hemisphere recorded twice from the right eye (red lines) and left eye (blue lines). Based on these interhemispheric difference signals a chiasm coefficient was calculated over 60-150 ms (ms) for the pattern onset and the 60-200 ms for the flash VEP. For adults the pattern onset was used to detect misrouting, and for children the flash $\mathrm{VEP}^{37}$. P1 and $\mathrm{P} 4$ were both 31 years of age. The signals in P1 are symmetrical, while misrouting is detected in P4. P3 was two years of age during VEP test, and has symmetrical responses. VEP test of P9, tested at the age of eight months old, has a negative chiasm coefficient (cc) of -0.98 , proving misrouting.

example RNA analysis to confirm the effects on exon 6 from the prediction programs. For c.310C > T; p.Pro104Ser functional analysis may be performed as described by Konno et al. ${ }^{39}$.

Unravelling the genotypic profile of all these cases does not provide a decisive clue for the variety in phenotypic presentation in this cohort. It is remarkable, that in our series of nine OCA4 patients, all patients showed obvious lack of pigmentation of skin, hair, and eyes. But, concerning visual function and ocular development, they were either on the poorer end of the spectrum for albinism, or were not affected at all. Even though visual function was not affected in P1, P2, and P3, sufficient diagnostic criteria for albinism proposed by Kruijt et al. were met, i.e. a molecular diagnosis, combined with a major criterion (iris translucency) and at least two minor criteria ( hypopigmentation of skin, hair, and fundus (all minor criteria) $)^{40}$.

Since the first patient reported in 2001, many patients with OCA4 have been described. In contrast to the homogeneous hypopigmentation phenotype we found in our cohort, in the literature the degree of pigmentation seems to vary from complete lack of pigmentation to very mild hypopigmentation ${ }^{1,6-30}$. While most reports describe pigmentation levels of skin and hair, ophthalmic details are usually scarce. Some studies report absence of nystagmus in some patients ${ }^{9,10,13,15,17-20}$. Visual acuities in OCA4 patients in earlier reports ranged from -0.1 to $1.5 \log$ MAR, with most patients having poor $\mathrm{VA}^{6,9,14,16,18,25,26,28,41}$. Only three patients were described with normal VA, and all three had only mild or no hypopigmentation ${ }^{9,18,26}$. Rundshagen et al. described a patient with VA of $0.2 \log$ MAR, subtle hypopigmentation, and nystagmus ${ }^{26}$. The second patient with good VA was of Japanese origin. His VA was $0.0 \operatorname{logMAR}$, he had brown hair and mild hypopigmentation of the skin, with the ability to tan. Other ophthalmic details were missing ${ }^{9}$. An Italian patient with good VA $(<0.2 \log$ MAR), no nystagmus, minimal iris translucency, and no fundal hypopigmentation is the only OCA4 patient decribed, to our knowledge, without foveal hypoplasia. In this patient misrouting was present, and molecular analysis revealed two variants in the SLC45A2 gene, c.619C4G (p.L207V) and c.606G4C (p.W202C) ${ }^{18}$. Until now, no patients have been described with evident lack of pigmentation of skin, hair, and eyes, but with normal ocular development, -i.e. normal VA, no nystagmus, no foveal hypoplasia and normal routing of the optic nerve fibers. Especially the absence of foveal hypoplasia is remarkable, occurring in less than $0.7 \%$ of albinism patients ${ }^{1}$.

It is still unclear why variants in genes responsible for melanin synthesis cause defects in the development of the visual system. It is assumed that lack of melanin in the retinal pigment epithelium is responsible for excessive crossing of the optic nerve fibers and foveal hypoplasia. Pigment epithelium-derived factor (PEDF) is a negative regulator of angiogenesis and plays an important role in the formation of the foveal avascular zone ${ }^{42}$. PEDF is 
decreased in the absence of tyrosinase, and therefore foveal hypoplasia could be caused by reduced PEDF ${ }^{43,44}$. However, a role for PEDF in chiasmal misrouting has not been established.

Generally, albinism patients with more severe hypopigmentation have more severe foveal hypoplasia and worse visual acuity ${ }^{1}$. Patients $\mathrm{P} 4-\mathrm{P} 9$ from this report conform to this phenotype. In contrast, P1, P2, and P3 demonstrate that normal foveal development, and normal routing of the optic nerve fibers can occur despite an evident lack of melanin. Non pathogenic variants in SLC45A5 may cause lightly pigmented skin and hair without an ocular phenotype. However, the variants found in P1, P2, and P3 were likely pathogenic, and importantly, the patients' hypopigmented phenotype was not restricted to skin and hair, as they did have grade 3-4 iris translucency.

The OCA4 phenotype of patients P1, P2, and P3 seems the very opposite of the phenotype of the FHONDA syndrome, caused by variants in SLC38A $8^{45-48}$. Patients with FHONDA have nystagmus, poor VA, severe foveal hypoplasia and misrouting, but no pigmentation defect. The FHONDA syndrome provided the first convincing evidence that lack of melanin is not the only determining factor in the combined occurrence of foveal hypoplasia and misrouting ${ }^{45}$.

The three OCA4 patients with normal visual development we describe in this report, are further proof that the relationship between pigmentation defect and ocular deficits in albinism is more complicated than previously thought. Further research is needed to unravel the mechanisms that cause some OCA4 patients to have a severe albinism phenotype, while others do not show any ocular deficit, apart from iris translucency.

\section{Data availability}

All data that are not included in this published article are available from the corresponding author on request.

Received: 5 February 2021; Accepted: 5 May 2021

Published online: 02 June 2021

\section{References}

1. Kruijt, C. C. et al. The phenotypic spectrum of albinism. Ophthalmology 125, 1953-1960 (2018).

2. Garrido, G., Fernández, A. \& Montoliu, L. HPS11 and OCA8: Two new types of albinism associated with mutations in BLOC1S5 and DCT genes. Pigment Cell Melanoma Res. 34, 10-12 (2021).

3. Kamaraj, B. \& Purohit, R. Mutational analysis on membrane associated transporter protein (MATP) and their structural consequences in oculocutaeous albinism type 4 (OCA4) - a molecular dynamics approach. J. Cell. Biochem. 117, 2608-2619 (2016).

4. Bin, B., Bhin, J., Yang, S. H., Shin, M. \& Nam, Y. Membrane-associated transporter protein (MATP) regulates melanosomal pH and influences tyrosinase activity. PLoS ONE 10, e0129273 (2015).

5. Newton, J. M. et al. Mutations in the human orthologue of the mouse underwhite gene (uw) underlie a new form of oculocutaneous albinism, OCA4. Am. J. Hum. Genet. 69, 981-988 (2001).

6. Gargiulo, A. et al. Molecular and clinical characterization of albinism in a large cohort of Italian patients. Investig. Ophthalmol. Vis. Sci. 52, 1281-1289 (2011).

7. Hida, T., Okura, M., Tanaka, T. \& Yamashita, T. A case of oculocutaneous albinism type 4: aberrant expression of SLC45A2 transcript with exon skipping. J. Dermatol. 41, 1019-1021 (2014).

8. Hutton, S. M. \& Spritz, R. A. Comprehensive analysis of oculocutaneous albinism among non-hispanic caucasians shows that OCA1 Is the most prevalent OCA type. J. Invest. Dermatol. 128, 2442-2450 (2008).

9. Inagaki, K. et al. Oculocutaneous albinism type 4: six novel mutations in the membrane-associated transporter protein gene and their phenotypes. Pigment Cell Res. 19, 451-453 (2006).

10. Inagaki, K. et al. Oculocutaneous albinism type 4 is one of the most common types of Albinism in Japan. Am. J. Hum. Genet. 74, 466-471 (2004).

11. Ko, J. M., Yang, J. A., Jeong, S. Y. \& Kim, H. J. Mutation spectrum of the TYR and SLC45A2 genes in patients with oculocutaneous albinism. Mol. Med. Rep. 5, 943-948 (2012).

12. Konno, T. et al. Oculocutaneous albinism type IV: a boy of Moroccan descent with a novel mutation in SLC45A2. Am. J. Med. Genet. Part A 149, 1773-1776 (2009).

13. Lewis, S. S. \& Girisha, K. M. Whole exome sequencing identifies a novel pathogenic variation [p. ( Gly194valfs * 7)] in SLC45A2 in the homozygous state in multiple members of a family with oculocutaneous albinism in southern India. Clin. Exp. Dermatol. 45, 409-413 (2019).

14. Li, H., Meng, S., Zheng, H., Wei, H. \& Zhang, Y. Bechara 1. Int. J. Dermatol. 47, 1198-1201 (2008).

15. Luo, D. et al. Molecular genetic study of 59 Chinese Oculocutaneous albinism families. Eur. J. Med. Genet. 62, 103709 (2019).

16. Marti, A. et al. Lessons of a day hospital: Comprehensive assessment of patients with albinism in a European setting. Pigment Cell Melanoma Res. 31, 318-329 (2018).

17. Mauri, L. et al. SLC45A2 mutation frequency in Oculocutaneous Albinism Italian patients doesn't differ from other European studies. Gene 533, 398-402 (2014).

18. Mauri, L. et al. Clinical evaluation and molecular screening of a large consecutive series of albino patients. J. Hum. Genet. 62, 277-290 (2017).

19. Okamura, K. et al. Impact of a 4-bp deletion variant ( rs984225803) in the promoter region of SLC45A2 on color variation among a Japanese population $€$ nermann: Happle syndrome due to a Case of Conradi-H u nonsense mutation of c. $245 \mathrm{G}>\mathrm{A}$ ( $\mathrm{p}$. W82 * ). J. Dermatol. 46, 295-296 (2019).

20. Okamura, K. et al. Genetic analyses of oculocutaneous albinism types 2 and 4 with eight novel mutations. J. Dermotol. Sci. 81, 140-142 (2016).

21. Okamura, K. et al. A 4-bp deletion promoter variant (rs984225803) is associated with mild OCA4 among Japanese patients. Pigment Cell Melanoma Res. 32, 79-84 (2019).

22. Okamura, K. et al. Oculocutaneous albinism (OCA) in Japanese patients: five novel mutations. J. Dermatol. Sci. 74, 173-174 (2014).

23. Park, S. H., Chae, H., Kim, Y. \& Kim, M. Molecular analysis of Korean patients with oculocutaneous albinism. Jpn. J. Ophthalmol. 56, 98-103 (2012).

24. Qiu, B., Zheng, X., Yang, J. \& Peng, C. Identification of five novel variants in chinese oculocutaneous albinism by targeted nextgeneration sequencing. Genet. Test Mol. Biomark. 22, 252-258 (2018).

25. Rooryck, C. et al. Molecular diagnosis of oculocutaneous albinism: New mutations in the OCA1-4 genes and practical aspects. Pigment Cell Melanoma Res. 21, 583-587 (2008).

26. Rundshagen, U., Zühlke, C., Opitz, S., Schwinger, E. \& Käsmann-Kellner, B. Mutations in the MATP gene in five German patients affected by oculocutaneous albinism type 4. Hum. Mutat. 23, 106-110 (2004). 
27. Straniero, L. et al. Two novel splicing mutations in the SLC45A2 gene cause Oculocutaneous Albinism Type IV by unmasking cryptic splice sites. J. Hum. Genet. 60, 467-471 (2015).

28. Suzuki, T. et al. A Korean case of oculocutaneous albinism type IV caused by a D157N mutation in the MATP gene. Br. J. Dermatol. 152, 174-175 (2005).

29. Tóth, L. et al. Identification of two novel mutations in the SLC45A2 gene in a Hungarian pedigree affected by unusual OCA type 4. BMC Med. Genet. 18, 27 (2017).

30. Xue, J. J. et al. Identification of a novel SLC45A2 mutation in albinism by targeted next-generation sequencing. Genet. Mol. Res. 15, 2-5 (2016).

31. Grønskov, K. et al. birth prevalence and mutation spectrum in danish patients with autosomal recessive albinism. Invest. Ophthalmol. Vis. Sci. 50, 1058-1064 (2009).

32. Wei, A. et al. A comprehensive analysis reveals mutational spectra and common alleles in chinese patients with oculocutaneous albinism. J. Invest. Dermatol. 130, 716-724 (2010).

33. Sengupta, M., Chaki, M., Arti, N. \& Ray, K. SLC45A2 variations in Indian oculocutaneous albinism patients. Mol. Vis. 10, 14061411 (2007).

34. Suzuki, T. \& Tomita, Y. Recent advances in genetic analyses of oculocutaneous albinism types 2 and 4. J. Dermatol. Sci. 51, 1-9 (2008).

35. Thomas, M. G. et al. Structural grading of foveal hypoplasia using spectral-domain optical coherence tomography a predictor of visual acuity?. Ophthalmology 118, 1653-1660 (2011).

36. Robson, A. G. et al. ISCEV guide to visual electrodiagnostic procedures. Doc. Ophthalmol. 136, 1-26 (2018).

37. Kruijt, C. C., De Wit, G. C., Talsma, H. E., Schalij-Delfos, N. E. \& Van Genderen, M. M. The detection of misrouting in albinism: Evaluation of different VEP procedures in a heterogeneous cohort. Investig. Ophthalmol. Vis. Sci. 60, 3963-3969 (2019).

38. Lasseaux, E. et al. Molecular characterization of a series of 990 index patients with albinism. Pigment Cell Melanoma Res. 31, 466-474 (2018).

39. Konno, T. et al. Functional analysis of OCA4 mutant sequences using under white mouse melanocytes. Pigment Cell Melanoma Res. 22, 235-237 (2009).

40. Pal, B. et al. A new phenotype of recessively inherited foveal hypoplasia and anterior segment dysgenesis maps to a locus on chromosome 16q23.2-24.2. J. Med. Genet. 41, 772-777 (2004).

41. Kausar, T. et al. Genetic studies of TYRP1 and SLC45A2 in Pakistani patients with nonsyndromic oculocutaneous albinism. J. Invest. Dermatol. 133, 1099-1102 (2013).

42. Provis, J. M., Dubis, A. M., Maddess, T. \& Carroll, J. Adaptation of the central retina for high acuity vision: cones, the fovea and the a vascular zone. Prog. Retin. Eye Res. 35, 63-81 (2013).

43. Lopez, V. M., Decatur, C. L., Stamer, W. D., Lynch, R. M. \& McKay, B. S. L-DOPA is an endogenous ligand for OA1. PLoS Biol. 6, 1861-1869 (2008).

44. Decatur, C. L. et al. The OA1 autocrine loop: in vivo and in vitro. Invest. Ophthalmol. Vis. Sci. 50, 1866 (2009).

45. van Genderen, M. M. et al. Chiasmal misrouting and foveal hypoplasia without albinism. Br. J. Ophthalmol. 90, 1098-1102 (2006).

46. Poulter, J. A. et al. Recessive mutations in SLC38a8 cause foveal hypoplasia and optic nerve misrouting without albinism. Am. J. Hum. Genet. 93, 1143-1150 (2013).

47. Campbell, P. et al. Clinical and genetic variability in children with partial albinism. Sci. Rep. 9, 16576 (2019).

48. Kuht, H. J. et al. SLC38A8 mutations result in arrested retinal development with loss of cone photoreceptor specialization. Hum. Mol. Genet. 29, 2989-3002 (2020).

\section{Acknowledgements}

The authors thank Herman Talsma for performing VEP recordings and help with obtaining the images in Fig. 1. Figure 2 was created by Gerard de Wit. The authors thank ODAS, Bartiméus Fonds and Landelijke Stichting Blinden en Slechtzienden for their financial support.

\section{Author contributions}

All authors contributed in the writing and reviewing of the manuscript. Talsma and Kruijt prepared Fig. 1, de Wit and Kruijt prepared Fig. 2.

\section{Funding}

This research was supported by the following foundations in the form of unrestricted funds: ODAS, Bartiméus Fonds and Landelijke Stichting Blinden en Slechtzienden (via contributions through UitZicht). The funding organizations had no role in the design or conduct of this research.

\section{Competing interests}

The authors declare no competing interests.

\section{Additional information}

Correspondence and requests for materials should be addressed to C.C.K.

Reprints and permissions information is available at www.nature.com/reprints.

Publisher's note Springer Nature remains neutral with regard to jurisdictional claims in published maps and institutional affiliations.

(c) (i) Open Access This article is licensed under a Creative Commons Attribution 4.0 International License, which permits use, sharing, adaptation, distribution and reproduction in any medium or format, as long as you give appropriate credit to the original author(s) and the source, provide a link to the Creative Commons licence, and indicate if changes were made. The images or other third party material in this article are included in the article's Creative Commons licence, unless indicated otherwise in a credit line to the material. If material is not included in the article's Creative Commons licence and your intended use is not permitted by statutory regulation or exceeds the permitted use, you will need to obtain permission directly from the copyright holder. To view a copy of this licence, visit http://creativecommons.org/licenses/by/4.0/.

(C) The Author(s) 2021 